\title{
La subjetividad política en el contexto latinoamericano. Una revisión y una propuesta*
}

\section{Political Subjectivity in the Latin American Context. A Review and a Proposal}

Luisa Fernanda Duque Monsalve ${ }^{1 \text { CvLAC }}$ - Carlos Darío Patiño Gaviria ${ }^{2 \text { CvLAC }}$ - Diego Alejandro Muñoz Gaviria $^{3} \mathrm{ORCID}_{\text {_ Edison Eduardo Villa Holguín }}{ }^{\mathrm{O} O \mathrm{RCI}}$ _ Jhon Jairo Cardona Estrada ${ }^{5} \mathrm{CVLAC}$

1,2,3,5 Universidad San Buenaventura. Medellín, Colombia. ${ }^{4}$ Academia Superior de Artes. México

Fecha correspondencia:

Recibido: noviembre 17 de 2015.

Aceptado: agosto 16 de 2016.

Forma de citar:

Duque, L., Patiño, C., Muñoz, D., Villa, E., \& Cardona, JJ. (2016). La subjetividad política en el contexto. Rev. CES Psicol., 9(2), 128-151.

\section{Open access}

(c) Copyright

Licencia creative commons

Ética de publicaciones

Revisión por pares

Gestión por Open Journal System

ISSN: 2011-3080

DOl: http://dx.doi.org/10.21615/ cesp.9.2.9

* Este trabajo se ha generado en el marco del proyecto de Investigación: "Formación de sujetos y construcción de subjetividades críticas en la configuración de tejido social en la ciudad de Medellín y en el área metropolitana, con jóvenes, educadores y líderes comunitarios"; financiada por la Universidad de San Buenaventura (USB) -Medellín- y el Instituto de Pensamiento y Cultura

Comparte

\section{Resumen}

El presente artículo expone una reflexión a partir de una revisión crítica de la producción investigativa (empírica y teórica) sobre subjetividad política en latinoamérica. Se tomaron como fuentes trabajos publicados entre 2006 y 2014 en español, hallados en bases de datos de ciencias sociales, teniendo como criterio de búsqueda las palabras claves "subjetividad política". Esta categoría en construcción se ha entendido como despliegue de la subjetividad social y como construcción de sentidos subjetivos en torno a lo público, en medio de las tensiones entre el mantenimiento del orden social y su transformación. Se identificaron subcategorías en la investigación de las subjetividades políticas y se propone que estas deben ser comprendidas en la diversidad de sus posibles formas, sin restringir su campo al de las "subjetividades instituyentes".

Palabras clave: Subjetividad, Política, Diversidad, Participación Política, Psicología Social, Psicología Política.

\section{Abstract}

This article presents a reflection on the research production (empirical and theoretical) regarding political subjectivity in Latin America. Certain works in Spanish published between 2006 and 2014, stored in databases of social sciences were taken as source, using the key words "political subjectivity" as the search criterion. This under-development category has been understood as the deployment of the social construction of subjectivity and as a construction of subjective meaning in regard to the public, amidst the tension between the maintenance of social order and its transformation. Subcategories were identified in the investigation of political subjectivities and it is proposed that this must be understood in the diversity of its possible forms, without restricting its field of institutive subjectivities.

Keywords: Subjectivity, Politics, Diversity, Political Participation, Social Psychology, Political Psychology. 
Pág 129

en América Latina (IPECAL) -

México - y llevada a cabo entre agosto del 2014 y diciembre del 2015.

\section{Sobre los autores: \\ 1. Psicóloga, Joven Investigadora COLCIENCIAS- Universidad de San Buenaventura, sede Medellín. Colombia.}

\section{Sociólogo, Magister en} Educación y Desarrollo Humano, cursa estudios Doctorales en Psicología en la Universidad de San Buenaventura- Medellín. Docente-Investigador de la Universidad de San Buenaventura, Medellín. Colombia.

3. Sociólogo, Magister en psicología, candidato a Doctor en filosofía UPB - Medellín. Docente-Investigador de la Universidad de San Buenaventura, Medellín. Colombia.

4. Licenciado en Lengua Castellana, Magister en Educación, cursa estudios Doctorales en el IPECAL (México), Docente Investigador Academia Superior de Artes. México.

5. Licenciado en Administración Educativa. Magister en Educación, director de la maestría en educación Universidad de San Buenaventura - Medellín, cursa estudios Doctorales en el Ipecal (México). DocenteInvestigador de la Universidad de San Buenaventura, Medellín. Colombia.

\section{Introducción}

Una revisión crítica de la producción académica en torno a la subjetividad política se hace necesaria puesto que, como lo ha señalado Díaz (2012a), existe una deficiencia en los antecedentes investigativos que buscan definir esta categoría, y sólo en la última década se ha intentado entender la conjunción entre subjetividad y política, dos conceptos que con anterioridad habían sido estudiados de manera independiente y por distintas disciplinas. Aunque es relativamente reciente, esta categoría ha estimulado una producción científica prolífica, principalmente en Colombia, con lo que ha logrado dar muestras de su capacidad heurística y ha ganado relevancia al permitir pensar problemas concretos que serían insuficientemente estudiados de otra manera (Díaz \& González, 2012). Además, se trata de un campo de estudio que se enriquece y sufre desplazamientos continuos, al punto que en artículos referidos temáticamente al campo de la subjetividad política se propone en perspectiva crítica un concepto diferente como es el de "subjetivación política" (Piedrahíta, 2012). Igualmente, la categoría ha sido usada en algunas investigaciones sin que sea conceptualizada de manera explícita (Bonvillani, 2006; Domínguez \& Castilla, 2011). Por otra parte, los procesos contemporáneos de participación política que incluyen nuevos y diferentes actores, como los Nuevos Movimientos Sociales (Torres, 2009), demandan horizontes de compresión teórica, entre los cuales sería pertinente incluir el concepto de subjetividad política. Las anteriores indicaciones hacen pensar que la categoría, que continúa en construcción, requiere una revisión crítica. De ahí el objetivo del presente artículo, que consiste en reflexionar sobre lo producido hasta el momento en torno a la subjetividad política, para identificar planteamientos centrales alrededor del tema y seguir proponiendo ideas que permitan continuar este camino de construcción teórica.

\section{Método}

La presente revisión se basó en un diseño de estudio documental, orientado a hacer un estado del arte, siguiendo una estrategia reflexiva que permitió reconocer los supuestos y planteamientos teóricos de los autores consultados. Las fuentes de información primaria fueron trabajos publicados entre 2006 y 2014 en español, hallados en bases de datos de ciencias sociales de América Latina (como Redalyc, SciELO, Dialnet, Google académico, Digitalia, EBSCO, entre otras), teniendo como criterio de búsqueda las palabras clave: "subjetividad política". La selección y muestreo de los artículos se hizo teniendo en cuenta el año de publicación, el desarrollo teórico, la inclusión de datos empíricos relativos a la categoría, la trayectoria de los investigadores y la diversidad de matices en el tratamiento de la categoría. Se dejaron de lado textos que redundaban en el tratamiento de la categoría de artículos ya seleccionados. Como unidad de análisis se tomaron, en primer lugar, los enunciados de los autores referidos al desarrollo teórico de la categoría subjetividad política; y, en segundo lugar, aquellos enunciados que hacían referencia a otras categorías o conceptos asociados a su estudio. La técnica empleada fue la observación documental y el instrumento para la producción de información consistió en una ficha que además de datos de identificación bibliográfica consignaba información acerca de los problemas de investigación, objetivos, metodologías, categorías, supuestos o planteamientos teóricos, tesis y/o resultados. Para el análisis se vació la información en una matriz, utilizando un archivo plano de Excel en el cual las ideas fueron categorizadas de manera inductiva, lo que permitió describir tendencias en el tratamiento de la subjetividad política y las categorías asociadas a su estudio, las cuales, a su vez, dieron lugar al análisis que se presenta en este artículo. A partir de lo anterior se identificaron vacíos, contradicciones y dificultades que sirvieron de base para hacer 
Pág 130

Las ciencias sociales contemporáneas hacen una reivindicación de la dimensión subjetiva humana en la producción y transformación del mundo social, y en las últimas décadas la cuestión de la subjetividad se ha puesto de relieve gracias a los aportes de pensadores como Foucault, Guattari, Bourdieu, Touraine y Geertz (Aquino, 2013). algunas contribuciones teóricas que se presentan en el último apartado de este texto. Cabe señalar que entre las investigaciones revisadas predominan ampliamente los diseños cualitativos de investigación, a excepción del trabajo de Imhoff, Gutiérrez y Brussino (2011) y algunas investigaciones que se apoyan parcialmente en datos estadísticos (Alvarado, Botero, \& Ospina, 2010; Samanamud, 2006).

\section{La Subjetividad: su carácter social}

Las ciencias sociales contemporáneas hacen una reivindicación de la dimensión subjetiva humana en la producción y transformación del mundo social, y en las últimas décadas la cuestión de la subjetividad se ha puesto de relieve gracias a los aportes de pensadores como Foucault, Guattari, Bourdieu, Touraine y Geertz (Aquino, 2013). En este punto, y reconociendo que los autores mencionados no son de procedencia latinoamericana, se hace importante traer a colación la propuesta de González Rey (2002), quien se ha convertido en un referente importante para el estudio de la subjetividad social, de la cual han bebido las recientes construcciones sobre subjetividad política. Para este autor, la subjetividad es una realidad ontológica del ser humano que, siendo psicológica, no atañe a una esencia interna del individuo, sino que por el contrario tiene un carácter social: se constituye en las experiencias compartidas y en las relaciones que las personas sostienen entre sí, en momentos históricos y en contextos culturales concretos. La subjetividad permite dar sentido a la diversidad de las experiencias humanas pues, como lo plantea Retamozo (2009), contribuye a generar, articular y producir significados. Esta creación de sentido no se reduce a las prácticas discursivas puramente racionales, antes bien, la base de la subjetividad es experiencial y los sentidos subjetivos integran procesos tanto simbólicos como afectivos.

La subjetividad social es concebida como una integración de sentidos y configuraciones subjetivas de diferentes espacios sociales, que forman un sistema en el cual lo que ocurre en un espacio social concreto está alimentado por lo producido en otros espacios sociales (González, 2008). La subjetividad social tiene un carácter complejo, que radica en que los sentidos subjetivos y las configuraciones conformadas por ellos se mantienen en entrelazamiento y constante desarrollo, debido a la interdependencia de los diferentes sistemas de los que la subjetividad es tanto producto como productora, y que abarcan desde la configuración subjetiva de un individuo hasta los sistemas sociales, pasando por diferentes subsistemas intermedios como la familia, la escuela, el trabajo, las relaciones comunitarias, etc. Por tanto, la subjetividad se va conformando a partir de las influencias recíprocas y las tensiones que se crean entre esta multiplicidad de sentidos sedimentados históricamente, procedentes de diversos espacios sociales de los que el sujeto participa. De ahí que cada sujeto llega a constituirse como tal gracias a los sentidos subjetivos que le han precedido en el plano social, cristalizados en la cultura. Al mismo tiempo, la subjetividad social sólo ha sido posible gracias al papel generativo de los sentidos subjetivos que surgen entre los individuos. El desarrollo de la subjetividad social en medio de estas tensiones y relaciones recursivas le confiere un carácter de devenir dinámico e inacabado, y por tanto impide pensar en universales que den cuenta de ella (González, 2007). En síntesis, para este autor, el concepto de "subjetividad social" hace referencia a una realidad humana que no se produce al interior de los individuos sino en las interacciones sociales. No obstante, a esta idea Torres (2009) agrega que la subjetividad es un medio para que los individuos y colectivos construyan la realidad y actúen sobre ella, en tanto son constituidos como sujetos. 
Pág 131

Aunque se reconozca que la subjetividad política no puede estar por fuera de los sistemas de la subjetividad social, queda por zanjar la cuestión sobre el estatuto o relativa autonomía que puede otorgarse a la categoría subjetividad política.
En definitiva, cabe decir que esta concepción de la subjetividad social, con su carácter relacional, dinámico, complejo, situado e histórico, cimienta las bases para una compresión de la subjetividad política, en el sentido que se expone a continuación.

\section{Subjetividad Política: categoría en construcción}

Algunos autores plantean que la subjetividad política se refiere a un momento susceptible de ser diferenciado pero que no es independiente de la subjetividad social (Díaz \& González, 2012). De acuerdo con esta idea, podría decirse que la política, entendida como conjunto de prácticas humanas, tiene una dimensión subjetiva, pero es inseparable del curso de la subjetividad social y aparece continuamente permeada e incluso constituida por los sentidos subjetivos provenientes de ámbitos sociales que tradicionalmente no han sido considerados del orden político. Las experiencias que el sujeto vive en escenarios como la familia o los espacios donde desarrolla sus aficiones, tienen su relevancia en la constitución de su subjetividad política. Así lo sugieren algunas investigaciones, como aquellas que tratan de la formación musical que deviene en formación ciudadana (Gómez, 2011), la creación de resistencias asociadas a identidades estético-culturales (Garcés, 2011), la socialización en contextos virtuales (Pedroza, Mesa, \& Bustos, 2013), entre otras. Sin embargo, también es cierto que las decisiones que se toman y las políticas que se crean en los escenarios gubernamentales tradicionales tiene un efecto -que suele ser imprevisible- en las producciones subjetivas de las personas (González, 2012).

Según González (2008), la subjetividad social forma un sistema en el cual lo que ocurre en cada espacio social está alimentado por producciones subjetivas, desdoblamientos y procesos de otros espacios sociales. Si se entiende la política como uno de dichos espacios sociales - $v$. gr. en su acepción institucional-, o incluso como forma de relación que opera en diversos espacios sociales, se puede concebir que la subjetividad política nunca está aislada del resto de espacios que configuran la subjetividad social (Díaz \& González, 2012), máxime si se acepta que los espacios sociales se hacen distinguibles a partir del enfoque que asume el observador, y no corresponden a subdivisiones concretas de la realidad que funcionan de manera autónoma. En su calidad de sistema, la subjetividad social abarca lo político al integrar sentidos subjetivos de "connotación política" (Díaz \& González, 2012) o con "implicaciones políticas" (González, 2012) procedentes de diversos espacios de la vida. Esto se explica porque lo político, al tener un carácter relacional (Arendt, 1997), opera en múltiples escenarios de participación, contradicción y polémica, que no son únicamente institucionales o estatales (González, 2012, Samanamud, 2006). Por tanto, la subjetividad política resulta de las interrelaciones de sentidos subjetivos provenientes de diferentes ámbitos de la vida social, porque lo político tiene la posibilidad de vivirse y desplegarse en esos múltiples espacios.

Ahora bien, aunque se reconozca que la subjetividad política no puede estar por fuera de los sistemas de la subjetividad social, queda por zanjar la cuestión sobre el estatuto o relativa autonomía que puede otorgarse a la categoría subjetividad política. Así, mientras que González Rey (2012) no reconoce un ámbito específico de la subjetividad política, al considerarla inmersa en la subjetividad social (González \& Díaz. 2012), desde otra perspectiva, Díaz (2012a) ha abogado por el reconocimiento de un dominio definido de la subjetividad política que tendría "su propia particularidad" y que se produciría "mediante procesos de subjetivación sobre la política y lo político, que siempre se despliegan en el ámbito de lo público, de lo que es común a todos" (p.17)¹.

1 Puede distinguirse un uso amplio de la noción de "subjetivación" para indicar en general, las formas en que se constituyen subjetividades, los procesos mediante los cuales, las experiencias y acciones del sujeto en espacios sociales concretos alimentan la producción de sentidos subjetivos y de constitución del sujeto; la subjetivación designa un proceso y no un estado. Sin embargo, 
De manera similar Alvarado, Ospina, Botero y Muñoz (2008) proponen que la subjetividad política se expresa mediante sentidos subjetivos múltiples que se interrelacionan constituyendo lo que han denominado "las tramas de la subjetividad política", y que en sus investigaciones han identificado como: la autonomía, la conciencia histórica y la posibilidad de plantearse utopías, la reflexividad, la ampliación del círculo ético, la articulación de la acción y sus narrativas, la configuración del espacio público como escenario de realización de lo político y la negociación del poder. En ese sentido, la subjetividad política se despliega como una matriz de sentidos subjetivos que tienen múltiples maneras de interconectarse, desarrollarse y expresarse, pero que tienen como su centro lo público.

Lo público se puede entender como "la esfera donde conversan las creencias, normas y procedimientos que coordinan la acción común y las acciones individuales para afrontar problemas y solventar conflictos" (Thiebaut, 1997, citado en Ocampo, Méndez, \& Pavajeau, 2008, p. 841). También se entiende como la esfera de las relaciones políticas que construyen la vida en común (Arendt, 1997). De manera que para algunos autores la subjetividad social se 'desdobla' en subjetividad política cuando los sujetos se abocan colectivamente a generar las condiciones que les permitan vivir en la diferencia, negociando en el ámbito de lo público lo que es común a todos (Díaz, Salamanca, \& Carmona, 2012). De acuerdo con esta tesis, la subjetividad política se produce mediante actos reflexivos que ubican al sujeto en un plano colectivo "donde el otro, lo otro me interesa en cuanto potencia para la constitución del nos(otros)" (Díaz, 2012a, p.99). Así, el 'yo' como ámbito de lo privado deja de estar contrapuesto al ámbito público (Herrera \& Garzón, 2014), el sujeto se desprivatiza y actúa con otros en la construcción de escenarios donde tiene cabida la pluralidad (Alvarado et. al., 2008). En consecuencia, lo político es comprendido como una realidad que se forma y expresa en el terreno del 'nosotros' (colectivo), pero que también "está significado por el 'mí mismo', cargado de los sentidos instituyentes de la esfera privada" (Alvarado, Ospina-Alvarado, \& García, 2012, p.247).

En síntesis, para este enfoque que reconoce un ámbito específico para la subjetividad política, ésta es construcción de sentido que tiene por objeto lo público: la creación de una vida común que incluya la pluralidad de lo humano, ya que es en los intercambios con los otros, en el intersticio del "entre nos" que tiene lugar la vida política, alimentada también por los aportes diferenciados de los individuos. Esta perspectiva está inspirada en la filosofía de Hannah Arendt², para quien la política tiene como características centrales el reconocimiento de la pluralidad de los seres humanos, el estar juntos como posibilidad de distinción e igualdad y la acción como creación que nace en el "entre nos" y se establece y desarrolla como relación en el ámbito de lo público (Alvarado, Patiño, \& Loaiza, 2012b, p.857).

En este sentido, para Bonvillani (2013) la subjetividad política aparece como un modo de ser y estar en el mundo, desde donde se vive la experiencia de encuentro/ desencuentro con los otros (lo común). Por supuesto, afirma esta autora, en la vida con los otros se producen tensiones que tienen lugar en el marco de relaciones de poder y en unas formas particulares de ordenamiento de lo social. De ahí que la subjetividad política, incluye los intentos de defensa y conservación, o los de resis-

el término subjetivación a menudo se emplea en un sentido más específico, para indicar la emergencia de condiciones subjetivas y formas de constitución del sujeto que escapan a los poderes dominantes (Tassin, 2012; Quintana, 2012, Vommaro, 2012; Piedrahíta, 2012). En este artículo se utiliza la primera acepción.

2 Para la filósofa: "La política trata del estar juntos, los unos con los otros, los diversos" (1997, p. 45), con lo cual la base de toda idea de política, según la autora, requiere un resguardo o cuidado de la pluralidad, acción política que permite la relación en la diversidad. En su libro ¿Qué es la política? será esta base de la política lo que permitiría enfrentar la decadencia de la época, signada por el totalitarismo. 
Pág 133

Dicho de otra manera, la subjetividad política no se refiere solamente a la configuración de sentidos subjetivos sobre lo público, sino que implica per se un potencial de transformación donde "las resistencias tienen asidero, las disidencias emergen, la constitución de lo nuevo se enuncia e instaura por lo que asume su condición de subjetividad política" (Díaz, 2012a, p.19-20). tencia y transformación de las formas en que los distintos poderes se han instituido a través de discursos, prácticas y prescripciones, es decir, del orden social.

En este marco, se plantea un cuestionamiento fundamental sobre la posibilidad de la transformación del orden social concomitante con la constitución de subjetividad política de talante crítico que opte por la emancipación ${ }^{3}$, ya que la lucha por alcanzarla "no se restringe al plano de la economía capitalista sino que comprende también el de la economía subjetiva" (Cubides, 2007, p.63). Para González (2002), la naturaleza compleja de la subjetividad, descrita en la introducción de este texto, significa que ella no se desarrolla de acuerdo a ningún principio ontológico inmutable o intencionalidad supra-histórica. Los sistemas biológicos, sociales, económicos, políticos, etc. que alimentan la producción de sentidos subjetivos no los fijan en una relación de causalidad unívoca desde una influencia objetiva-externa (González, 2007), sino que al constituirse a partir de la relación recursiva entre sentidos subjetivos provenientes de diferentes sistemas y por parte de la creatividad de los sujetos, se encuentra en desarrollo y admite la emancipación. La imposibilidad de que la subjetividad sea "domesticada", la ubica entonces como "un elemento altamente subversivo, en tanto su desarrollo y desdoblamientos no se pueden controlar ni dirigir desde la intencionalidad humana, sujetándola a algún sistema universal de valores" (González, 2007, p.23).

En consonancia con esta idea, existe una perspectiva que asocia la subjetividad política a la generación de sentidos y prácticas orientados a la emancipación, y se considera que el sujeto político es aquel que procura una transformación de la forma dominante de funcionamiento de la sociedad. Por ejemplo, Díaz (2012a), en una de las acepciones que plantea, declara que la subjetividad política "se encarna en un sujeto quien preocupado por el devenir de la humanidad-expresada en sus cercanos de casa, barrio, ciudad, país- ayuda en la formulación y concreción de proyectos cada vez más humanizantes, comunes y alternos a los dominantes" (Díaz, 2012a, p. 102).

Desde este punto de vista, el sujeto político es aquel que, mediante acciones de reflexividad, crea sentidos subjetivos transformadores y se convierte en protagonista de la política: "la subjetividad política es potencia creadora de la novedad instituyente de lo social" (Díaz, 2012a, p.15) ${ }^{4}$. Dicho de otra manera, la subjetividad política no se refiere solamente a la configuración de sentidos subjetivos sobre lo público, sino que implica per se un potencial de transformación donde "las resistencias tienen asidero, las disidencias emergen, la constitución de lo nuevo se enuncia e instaura por lo que asume su condición de subjetividad política" (Díaz, 2012a, p.19-20). BonviLlani (2012), por su parte, asume la distinción entre lo político y lo policial propuesta por Rancière (2006) $^{5}$, a partir de la cual afirma que la subjetividad política tiene lugar cuando emerge un sujeto que, en procura de su emancipación, despliega su potencia subjetiva en tensión con las condiciones en las que vive, en una lucha por desnaturalizar estructuras y modos de relación, promoviendo la desidentificación frente a un orden establecido y un papel adjudicado en el mundo social.

Esta perspectiva enfatiza la potencia para de-construir y generar prácticas actualizantes de ordenamientos de vida colectiva (Alvarado et al., 2010), pero existen otras

3 Por emancipación se puede entender la voluntad humana de hacerse consciente y responsable de una acción en el mundo donde la posibilidad de la creación colectiva sea posible. Dicha voluntad deviene proceso en la constancia, siendo así la emancipación una búsqueda política permanente (Marx, 2009).

4 Estas subjetividades instituyentes o constituyentes se caracterizarían por introducir novedades en lo social, en contra o por fuera de lo estructurado (Torres, 2009).

5 El autor, en una clara herencia foucaultiana, asume lo político como lo emancipatorio, estableciendo con ello una distinción entre lo político - emancipador y lo policivo - administrativo. En una lectura crítica a las formas de administración de lo existente, lo político sólo tiene sentido como apertura a nuevas posibilidades, a emancipaciones humanas y políticas (Rancière, 2006). 
interpretaciones que no ponen un acento en el potencial emancipador de la subjetividad, sino que resaltan las tensiones entre esas posibilidades y las tendencias opuestas a perpetuar el orden existente. Torres (2009) reconoce que lo subjetivo se pone tanto del lado instituido, que legitima y mantiene el poder hegemónico, como del lado instituyente, en tanto acción de resistencia que se expresa en la creación de otras relaciones sociales. Entre tanto, Martínez y Cubides (2012) insisten en la dificultad para que lo instituyente esté completamente por fuera o separado de los escenarios y mecanismos del orden instituido, incluyendo los modos de participación política convencional. En efecto, para estas autoras es común encontrar mezclas entre lo tradicional y lo alternativo porque el sujeto está inmerso en un campo de fuerzas desde el cual diversos vectores contribuyen con su proceso de construcción subjetiva. También Díaz et al. (2012) entienden que la subjetividad política puede contribuir a preservar temporalmente el imaginario instituido que se asuma pertinente para una sociedad en particular, o también puede ayudar a "concretar nuevos imaginarios instituyentes que viabilicen proyectos de mayor autonomía individual y social" (p.53).

A partir de lo anterior, puede inferirse que, para algunos autores, la subjetividad política devendría a partir de una tensión fundamental, entre sentidos instituidos en lo social que tienden a mantener el status quo, de un lado, y la creación de nuevos sentidos que se podrían erigir en procura de la emancipación, de otro. Ahora bien, nuestra interpretación es que, para comprender teóricamente esa tensión fundamental, los investigadores de la subjetividad política han apelado a diversos autores y tradiciones, que, con distintas categorías y enfoques teóricos, explican esta relación entre lo dado y lo emergente. No se trata de un mismo corpus teórico sino de diferentes tradiciones que dan cuenta de una lógica de "tensión". Para algunos, la tensión se produce entre procesos de sujeción y de subjetivación (Retamozo, 2011). En este sentido, Foucault es recurrentemente citado: por ejemplo, Cubides (2007) referencia a Foucault (1991) para plantear que la subjetividad se organiza como pliegue e implica un entrecruzamiento de los efectos del ejercicio institucional del poder y de procesos reflexivos del individuo sobre sí mismo. Por otra parte, Herrera y Garzón (2014) citan a Foucault (1996) quien afirma que la subjetividad

Encarna una tensión entre aquello que se ha constituido como sujeto a través de los diferentes aparatajes y prácticas sociales y el trazo de libertad que no queda completamente inscrito en esos aparatajes, pero que no obstante no puede manifestarse ni constituirse más que por su mediación (p.63).

Por otra parte, autoras como Martínez y Cubides (2012), al igual que Díaz (2012a), acuden a la propuesta de Castoriadis (1997), quien sostiene que la imaginación permite a los seres humanos trascender el imaginario social de lo instituido para acercarse a la creación del orden deseado. El mismo Díaz (2012a) referencia la relación entre biopolítica y biopotencia, donde la biopolítica como ejercicio del poder político sobre el cuerpo y todos los espacios de la vida se ve limitada por la potencia de la vida que no se deja colonizar por completo (Pál, 2006 citado por Díaz, 2007). Por su parte, Zemelman (2012), que no habla de subjetividad política pero sí de subjetividad, desarrolla una reflexión sobre la tensión entre las condiciones estructurales que conforman la esencia social del individuo y su capacidad reactiva consciente. En este contexto, el autor defiende la posibilidad del sujeto actuante en momentos concretos del devenir histórico y la necesidad de una constante ampliación de la subjetividad como fuerza modeladora de la sociedad. Por último, desde posturas de inspiración psicoanalítica, se sostiene que allí donde circula el deseo, el poder 
Pág 135

Nos parece necesario insistir en que, si bien se reconoce que la subjetividad no está dirigida por alguna invariante universal y por tanto es susceptible de transformación creativa, las acciones humanas productoras de subjetividad se sitúan en contextos culturales específicos que ofrecen un margen de posibilidad a los cambios subjetivos. no puede instalarse totalmente, puesto que es el inconsciente lo que se resiste al poder y crea posibilidades de desestabilizar la identidad y generar performatividad (García, 2014).

Las anteriores tradiciones teóricas, cada una con sus matices, dan una base para que los investigadores entiendan el desarrollo de la subjetividad política como emergente de tensiones, que no sólo se instaura como reproducción de sentidos que perpetúan formas culturales dominantes, sino que alberga un potencial que aparece como resto de libertad, posibilidad, resistencia, deseo, como aquello irreductible que no se deja atrapar, sino que desafía, escapa e irrumpe.

Sin embargo, nos parece necesario insistir en que, si bien se reconoce que la subjetividad no está dirigida por alguna invariante universal y por tanto es susceptible de transformación creativa, las acciones humanas productoras de subjetividad se sitúan en contextos culturales específicos que ofrecen un margen de posibilidad a los cambios subjetivos. En esta medida, reconocer las posibilidades de emancipación, no se puede traducir en la defensa de una libertad abstracta o absoluta del sujeto para crear sus condiciones de vida o realizar transfiguraciones subjetivas, pues, en todo caso, la subjetividad seguiría estando condicionada, aunque no determinada, por la interrelación de los sentidos subjetivos surgidos en el devenir de las relaciones humanas, en los distintos espacios sociales, cuya emergencia el sujeto no puede dirigir de una manera unilateral. Siguiendo a González (2007), se puede decir que el sujeto no es capaz de aprehender completamente con su conciencia los múltiples desdoblamientos de su subjetividad, cuyos efectos en muchas ocasiones quedan por fuera de su control e intencionalidad.

Cabe señalar la posibilidad de que los potenciales para la emancipación no lleguen a realizarse, ya que la producción subjetiva se encuentra con bordes ${ }^{6}$ que toman la forma de múltiples condiciones de subjetivación, presentes en cada contexto sociohistórico determinado, pero que no operan como límites definibles y eternos. En concordancia con esta idea se puede plantear que la modificación, reorganización y creación permanente de sentidos subjetivos no implica la necesaria conformación de un sujeto emancipado. En palabras de Retamozo (2009), "la contingencia de la que partimos y la historicidad, tanto de los sujetos como del orden social, nos orientan en la necesidad de indagar en las potencialidades y límites de los sujetos históricos emergentes" (p.115). Según esta idea, los potenciales en muchas ocasiones permanecen en estado latente. De ahí que sea necesario valorar cada situación particular de ruptura, en relación con su contexto de producción y consecuencias. Es decir, las nuevas formas de subjetivación no siempre apuntan a la emancipación, sino que pueden tener componentes ideológicos que operan en sentido contrario, por lo que habría que considerarlas para discernir "entre sistemas conservadores y sistemas orientados al desarrollo” (González, 2007, p.23).

\section{Categorías asociadas al estudio de la Subjetividad Política}

Las investigaciones sobre subjetividad política se han ocupado principalmente de visibilizar la emergencia de tendencias subjetivas críticas e instituyentes, por lo que se han propuesto enfoques como el de la diferencia (Piedrahíta, 2013) o el de la afirmación (Escobar, 1996 citado por Alvarado et. al., 2010). Tales enfoques propenden por el reconocimiento de experiencias cotidianas que generan apuestas políticas alternativas, produciendo rupturas, líneas de fuga, resistencias y disidencias a partir

6 Apelamos a la metáfora de los bordes y los límites que Soto (2001) utiliza para dar cuenta de la borrosidad de las categorías propias de la psicología social. 
de acciones creativas que niegan la repetición irreflexiva de formas de vida hegemónicas y homogenizantes. Para dar cuenta de estas subjetividades, los investigadores construyen sentidos alrededor de lo que se podría nombrar como dimensiones, procesos de constitución y expresiones de la subjetividad política que se despliegan de manera recursiva en su producción.

Habría que señalar que la subjetividad, sea entendida como realidad (González, 2002), como campo problemático o como perspectiva (Torres, 2009), se refiere al espectro amplio de la construcción humana de sentidos, que operan en las relaciones entre las personas y su mundo social, significando las prácticas sociales de una cultura (Aquino, 2013). Por ello, en el estudio de la subjetividad política, los investigadores han apelado, desde sus diferentes marcos de comprensión, a una variedad de categorías que permitirían dar cuenta, de una manera más concreta, de los sentidos de la acción social que en sí mismos son inaprehensibles. En la literatura especializada se hace una referencia frecuente a los afectos, la reflexividad, la memoria, la conciencia histórica, las narrativas, la acción política, la socialización política, la identidad social, el territorio, los significados, entre otros. Es la pretensión de este apartado hacer un análisis de cómo esas categorías han emergido y han sido relacionadas con la configuración de la subjetividad política.

Para empezar, está la dimensión afectiva de la subjetividad política. Desde el marco de la psicología social cognitiva, se recalca la necesidad de estudiar el conjunto de emociones y no sólo de cogniciones que tienen los sujetos en relación a la arena política (Imhoff et al., 2011); pero también desde las premisas de la psicología histórico-cultural, la subjetividad implica la presencia inseparable de procesos simbólicos y afectivos en la constitución de los sentidos subjetivos. De suerte que toda la vida política es en realidad afectiva, ya que las experiencias de encuentro y desencuentro que se producen en la vida en común siempre están cargadas de emociones, pasiones y sentimientos. Sin embargo, los investigadores que asumen esta perspectiva, no siempre hacen explícita la dimensión afectiva presente en los entramados de sentidos subjetivos que se construyen en los procesos de investigación, lo que no excluye que hagan una referencia recurrente a diversos sentimientos. Incluso desde algunos planteamientos se reconoce que las subjetivaciones políticas se basan principalmente en el deseo y el afecto, antes que en los procesos de raciocinio (Piedrahíta, 2013).

Simultáneamente, Zibechi (2007) reconoce que los afectos son los que organizan el barrio-comunidad, y en especial el dolor adquiere un papel cohesionador de dichas instancias. No obstante, Díaz et al. (2012) señalan que los afectos se encarnan en las experiencias concretas con las que se va formando la subjetividad política, las cuales suelen vivirse con miedo, dolor e indignación por parte de los sujetos, pero, a su vez, se logran afrontar con coraje, pasión y esperanza. Los sentimientos, y no sólo las cogniciones, se tornan catalizadores de la decisión de asumir posición frente a las realidades que se viven y de emprender acciones políticas (Vargas, López, \& Guevara, 2009). Por otra parte, la militancia política aparece imbricada afectivamente con sentimientos de dolor y angustia asociados a la falta de reconocimiento, pero también del disfrute y la emocionalidad auto-afirmativa que el sujeto siente cuando descubre su potencia creadora en la vida política (Bonvillani, 2012), de modo que la relación que se establece con la política tiene un impacto emocional en la conformación de la autoimagen (Bonvillani, 2006). Estos últimos sentimientos se asocian al placer de formar con otros la comunidad que se desea (Díaz, 2012a), mientras que el humor y la risa, por ejemplo, asociados a la acción política en la "carnavalización de vida", generan sentidos que trastocan los textos y valores dominantes (García, 2013). 
Pág 137

En los procesos de constitución, pero también en los de vivencia y expresión de la subjetividad política, está presente una dimensión emocional.
La importancia de la dimensión afectiva también es rescatada en los procesos de socialización política. Por ejemplo, para Alvarado et al. (2008), es imperativo potenciar la afectividad de los sujetos políticos para que estos puedan reconocerse a sí mismos y a los otros en su diferencia. Dicho de otro modo, en los procesos de constitución, pero también en los de vivencia y expresión de la subjetividad política, está presente una dimensión emocional. Ahora bien, el cuerpo político es considerado como depositario de imágenes cargadas de emoción, como el lugar de vivencia de los afectos, que lleva en sí las marcas de las experiencias humanas (Lara-Salcedo, 2010), en este sentido, puede decirse que la subjetividad política también está "encorpada" (Díaz, 2012b). En el cuerpo se encarna aquello que en ocasiones no es posible narrar (Alvarado, 2014), pero también lo que se simboliza de los discursos políticos. El sujeto político es necesariamente un sujeto con cuerpo, puesto que este es el primer territorio del poder, que puede alojar tanto prácticas de dominación como de liberación. Además, el cuerpo es sitio constante de intervenciones del sujeto político y vehículo de su acción: se cambia su estética, se esconde, se enfrenta a otros en una lucha a veces violenta, se acomoda a las diversas actividades que demanda la militancia, etc. (Díaz, 2012a).

Entre los procesos constituyentes de la subjetividad se destaca la reflexividad, puesto que a través de ella la propia actividad se vuelve objeto explícito para el sujeto (Díaz, 2012a). Así, la reflexividad posibilita la transformación subjetiva (Alvarado et al., 2008), en tanto permite la identificación de prácticas de dominación que han colonizado al sujeto y el consecuente descubrimiento de lo que podría constituirse como opciones de liberación que, según Foucault, están posibilitadas por prácticas de cuidado de sí (Cubides, 2007). Dicho ejercicio de la libertad a partir del gobierno de sí mismo "tiene una dimensión política, en la medida en que permite a los sujetos resistirse a las formas de poder ejercidas cotidianamente y que los sujetan" (Ocampo, et al., 2008, p.848). Mientras tanto, en la narrativa como vía reflexiva "nos descubrimos y nos reinterpretamos a nosotros mismos, haciendo inteligible la complejidad de la acción humana y social" (Lara-Salcedo, 2010, p. 362).

El acto de pensar (se) también ayuda a formar un sentido de coherencia e identidad política, por más móvil que esta sea (Díaz, 2012a); precisamente una de las funciones de la subjetividad, tal como las enuncia Torres (2009), es la construcción de la identidad, no sólo personal, sino especialmente social. En efecto, la reflexión no se hace únicamente sobre el sí mismo, sino que se centra en la relación del sujeto con el mundo del que participa y crea. Los procesos de reflexividad implican una ampliación del yo hacia la esfera pública porque la conciencia nunca es conciencia sólo de sí: la "toma de conciencia" lleva al sujeto a cuestionarse su lugar en la sociedad (Freire, 1985), y cuando la reflexividad se enfoca en el plano social conduce a formular preguntas relativas al tipo de sociedad que se desea y los medios para construirla (Díaz et al., 2012). El pensamiento reflexivo establece la relación entre los hechos y sus consecuencias, así como entre el pasado y el presente, mientras que, mediante actos de memoria, el sujeto puede volver sobre sí mismo y sobre las raíces históricas que han configurado su realidad. La conciencia que se genera de tal modo permite entender que se puede ser protagonista de la historia (Alvarado et al., 2010).

Por otra parte, las investigaciones dan cuenta de la dinámica de ciertos procesos agenciantes de la subjetividad. De acuerdo con Martínez y Cubides (2012), lo agenciante tiene que ver con lo que apalanca, provoca o promueve el fortalecimiento de la capacidad política del sujeto. Por ello se ha considerado pertinente reconocer en 
esta categoría a los acontecimientos y las condiciones socio-históricas como procesos que agencian la configuración de la subjetividad política.

Así, las investigaciones tienden a identificar como agenciantes ciertos "acontecimientos" (Alvarado et al., 2010), como situaciones, eventos, o condiciones que logran alterar la cotidianidad del sujeto e inciden en su forma de considerar y actuar sobre la realidad social. Cabe señalar que no se trata de hechos objetivos o externos que causan por sí mismos una movilización del sujeto, lo importante es la subjetivación que se hace del hecho (Samanamud, 2006). Alvarado et al. (2010) aclaran que un acontecimiento es más que un evento o suceso histórico, sólo se produce cuando la experiencia configura una trama o narrativa que hace una ruptura en el curso naturalizado de las vivencias cotidianas. La mediación de procesos reflexivos, los ejercicios de memoria, la construcción de narrativas, entre otros, posibilitan que una realidad concreta sea reconocida y leída críticamente: la adversidad debe ser reconocida como injusticia, sólo así puede volverse agenciante (Vargas et al., 2009). Estas lecturas también son posibilitadas por la atribución de significados y mediaciones simbólicas, sociales y políticas, que permiten que las necesidades sean reelaboradas como reivindicaciones o demandas (Torres, 2009), lo que hace que una realidad se asuma como transformable y se piense y actúe en razón de dicha transformación. ${ }^{7}$

Se habla aquí de condiciones que movilizan el deseo del sujeto político, que en tanto "falta" provoca una disposición para la acción (Retamozo, 2009), por ejemplo, la pobreza vivida (Bonvillani, 2012; Díaz, 2012a), el terror ante ciertos dispositivos biopolíticos (Díaz et al., 2012), distintos tipos de violencia (Alvarado et al., 2010), las contradicciones y conflictos de la vida urbana (Torres, 2009), la exclusión racial y la marginación (Samanamud, 2006), entre otros. Pero no se trata de condiciones que necesariamente son valoradas como "negativas" por los sujetos.

De otro lado, las investigaciones señalan que los procesos organizativos de acción social y política, las redes, las organizaciones comunitarias y especialmente los movimientos sociales, se han convertido en escenarios privilegiados para la formación y expresión de subjetividades políticas. Estas asociaciones entre personas procuran el logro de intereses comunes en torno a su bienestar, la resolución de problemas que los afectan y la mejora de sus condiciones de vida. Se trata, en todos los casos, de articulaciones sociales que adquieren un sentido político.

Específicamente, los movimientos sociales son expresión de la subjetividad política orientados a reivindicaciones diversas (Alvarado et al., 2010). Para ello se organizan como intentos colectivos y conscientes, que utilizan medios no institucionales de acción (Alvarado, Patiño, \& Ospina, 2012a). Se caracterizan además por buscar la autonomía, la descentralización y la participación (Muñoz-López \& Alvarado, 2011; Ocampo et al., 2008) mediante demandas, críticas y proyectos. Estas subjetividades politizan los espacios sociales y en determinado momento trascienden la protesta para generar alternativas de consecución y manejo de sus recursos y procesos (Alvarado et al., 2012a).

La pertenencia a esta clase de organizaciones forma políticamente a los sujetos, no sólo por los saberes que allí circulan sino principalmente por las experiencias de acción colectiva. Se trata de experiencias con otros que ayudan a configurar, trasfor-

7 Parece que se trata de un bucle recursivo entre las condiciones socio-históricas y los procesos subjetivos. La agencia no surge por sí misma como consecuencia de hechos "objetivos", pero tampoco es construida sin más desde una subjetividad ajena a las condiciones materiales de existencia, por lo demás, estas últimas no están aisladas, ni en su emergencia ni en su devenir, de los sistemas de la subjetividad social. 
Pág 139

Los movimientos sociales generan un constante desafío a las formas de dominación (García, 2014) y mantienen la subjetividad política en creación, movimiento y expresión. Esto es así porque los múltiples sujetos de la política con sus búsquedas diferenciadas, mantienen en tensión la arena política, ya que permanentemente entran en confrontación y negociación en el ámbito público. mar o afirmar la subjetividad política, porque entre otras cosas, propician el debate, la crítica, la construcción de acuerdos y construcción de opciones de vida conjunta (Díaz, 2012a; Martínez \& Cubides, 2012).

En estos movimientos se produce lo que algunos autores han entendido como el desdoblamiento de la subjetividad social en subjetividad política, ya que en ellos se desdibujan los límites entre el yo y el otro, se produce una "ampliación del círculo ético" en la medida en que se crean responsabilidades y deseos de cuidado hacia la comunidad y la sociedad (Alvarado, 2014). Frecuentemente estas colectividades surgen y se mantienen a partir de la politización de escenarios concretos de la vida cotidiana, en territorios situados en relación con los cuales se generan o resignifican identidades colectivas y culturales (Alvarado et al., 2012a; Samanamud, 2006; Torres, 2009; Vommaro, 2012). Precisamente, la subjetivación política implica el "sentimiento de un nosotros" con quienes se comparten los mismos sufrimientos y, también, los mismos sueños de transformación de la opresión (Bonvillani, 2012).

Este nosotros se conforma mediante sedimentaciones subjetivas en un proceso histórico de fijación de ciertos sentidos compartidos desde donde se definen identidades y alteridades (Retamozo, 2009). De hecho, en estas organizaciones, antes que relaciones políticas, lo que se establecen son relaciones de afecto y amistad (Díaz, 2012a), es decir, en su núcleo se encuentran procesos subjetivos que más allá de la búsqueda de satisfacción de necesidades se consolidan a través de sentimientos intensos, tradiciones, sistemas de valores y prácticas cotidianas (Vommaro, 2012) La cohesión es proporcionada por lazos de solidaridad, reciprocidad, pertenencia y reconocimiento mutuo, ya que se trata de espacios de encuentro e intercambio de historias e intimidades (Alvarado et al., 2008) que se viven con "la piel" de la subjetividad política (Bonvillani, 2013). Torres (2009) señala que, en el estudio de los movimientos sociales, los procesos subjetivos, "Ilámense ideología, conciencia, psicología colectiva, creencia generalizada, frustración, agravio moral, identidad, orientación cultural o marcos interpretativos" (p.63), son ineludibles, ya que se considera que tales procesos son estructurantes de los movimientos.

Los movimientos sociales generan un constante desafío a las formas de dominación (García, 2014) y mantienen la subjetividad política en creación, movimiento y expresión. Esto es así porque los múltiples sujetos de la política con sus búsquedas diferenciadas, mantienen en tensión la arena política, ya que permanentemente entran en confrontación y negociación en el ámbito público. Este juego de tensiones mantiene la vitalidad de la política a diferencia de las formas reificadas que adquieren los sistemas políticos tradicionales (González, 2012). Por esta razón, los movimientos representan modos de la subjetividad política indispensables para cualquier proyecto democrático (Vargas et al., 2009). De acuerdo con Torres (2009), estos movimientos "han sido instituyentes de buena parte de los rasgos progresistas de las sociedades contemporáneas" (p.71), es decir, no sólo expresan subjetividades, sino que contribuyen a generarlas.

De otra parte, en el proceso de constitución de la subjetividad política, la socialización política incluye al conjunto de experiencias que forman la identidad social del sujeto, lo que implica la apropiación de normas, valores y comportamientos políticos propios de la comunidad de pertenencia. Sin embargo, no tiene únicamente la función de reproducir el sistema político, sino que a partir de la socialización también es posible que se potencien instancias subjetivas capaces de propiciar transformaciones (Alvarado et al., 2012). Las incitaciones que hacen parte del proceso de socialización 
no son suficientes o concluyentes en la configuración de la subjetividad política, que además requiere del trabajo autoconstitutivo del sujeto (Díaz, 2012a).

Tradicionalmente la familia, la escuela, la universidad, los escenarios de interacción con pares y los medios de comunicación han sido considerados como los principales agentes socializadores, ya que ellos hacen circular no sólo discursos y contenidos políticos manifiestos sino que en sus espacios se vivencian prácticas y modos de relación -v. gr. de poder y de género- (Alvarado, 2014; Lozano, 2008) que pueden ser entendidos como despliegues de la subjetividad política operantes en esos espacios y tienen a su vez, alcances en la constitución de subjetividades. En el marco de las anteriores consideraciones, se ha planteado que los procesos de socialización política direccionados desde instituciones como la escuela y la universidad tendrían que promover procesos cotidianos de vivencia de lo público, de educación en y para la democracia participativa y desde la reivindicación de derechos, elementos que pueden generar rupturas en las formas de dominación instauradas en esos mismos escenarios, y que no se reduzcan a la transmisión de conocimientos sobre el sistema político o a la generación de competencias individuales para la convivencia (Alvarado et al., 2008; Ocampo et al., 2008; Palacios-Mena \& Herrera-González, 2013; Portela \& Portela, 2010).

En síntesis, la socialización política se produce en variados escenarios desde donde se contribuye a la formación de subjetividades, a través de la circulación de actitudes, emociones, valores, creencias, conocimientos y capacidades relativas a la vida política (Ocampo et al., 2008); además, la socialización política se vislumbra como una posibilidad de incitar la emergencia de sujetos protagonistas de su historia social (Alvarado et al., 2008).

Para finalizar, se quiere hacer mención de la categoría acción política. Ella es tanto expresión de la subjetividad política como productora de la misma, ya que la impacta y la transforma (Retamozo, 2009; Vommaro, 2012). Según Zemelman (2012) puede ser entendida como la encarnación de una voluntad que en la medida en que se realiza contribuye a la propia ampliación de la conciencia del sujeto y afirma su capacidad. La acción política es realización viva de la subjetividad y se dirige a propósitos como: generar cambios en las relaciones de poder propias de lo público para reconfigurar creativamente órdenes y discursos, lo que implica posibilidad de iniciativa y capacidad de decisión (Alvarado et al., 2008; Domínquez \& Castilla, 2011); consolidar resistencias que se materializan en propuestas de cambio (Martínez \& Cubides, 2012); tomar decisiones y concretar proyectos organizativos comunitarios -la acción política nunca es la actividad de un individuo aislado- (Díaz, 2014). En términos generales, la acción política se ejercita en las diversas formas de participación política convencional y no convencional. Para Vargas et al. (2009), el sujeto político es el que actúa concretando las posibilidades de transformación de sus realidades. Por tal motivo, en términos de subjetividad política, no basta con que el individuo tome una posición respecto a las condiciones de injusticia que vive, sino que debe existir una acción que pretenda incidir sobre esas condiciones.

\section{La diversidad de la subjetividad política: una propuesta}

Se ha reconocido que la subjetividad política se constituye en la interrelación de múltiples sentidos subjetivos, cuyo desarrollo no se puede direccionar en términos de un resultado que se pueda prever y controlar. También se ha dicho que a ella le es inherente un potencial para la transformación, pero que así mismo vive entre las sedimentaciones y regularidades del orden social imperante. Lo anterior permite 
Pág 141

La subjetividad política deviene en medio de las tensiones; no entre los sujetos y una estructura social inmóvil y monolítica, sino propiamente "entre" sujetos -individuales o colectivos-, algunos de los cuales representan, de manera consciente o inconsciente, los intereses de esa estructura y otros que pretenden posicionarse en contra o por fuera de ella. considerar la diversidad de la subjetividad política que no se restringe a formas instituyentes. La pertinencia de sustentar esta idea reside en la identificación de la tendencia en algunas investigaciones a desconocer la existencia de subjetividades políticas que contribuyen a legitimar y perpetuar el orden social dado, y aun cuando se reconoce que la subjetividad política emerge en medio de las tensiones entre lo instituido y lo instituyente en el imaginario social, parece que se niega el carácter político y aún creativo de aquellas subjetividades que luchan por mantener lo instituido. Por el contrario, se quiere defender que es necesario considerar la subjetividad política en la diversidad de sus despliegues ${ }^{8}$.

De acuerdo con Mouffe (2007), lo político se refiere al espacio de conflictividad inherente a las relaciones entre seres humanos, donde éstos en lugar de enemigos, pueden llegar a considerarse adversarios con legitimidad para controvertir posturas, con posibilidad de actuar sobre las cuestiones en disputa y renegociar los acuerdos sociales en el contexto de una diversidad que no debe desaparecer. Estos conflictos pueden dirimirse a través de la discusión argumentada entre adversarios, quienes se asumen en relación agonista y pueden establecer acuerdos provisionales. Sin embargo, también existe la posibilidad de que las luchas de poder e intereses conduzcan a dinámicas de dominación, exclusión, inequidad y violencia, manifiestas en la vida pública (Ocampo et al., 2008). En concordancia con esta noción de lo político, la subjetividad política, deviene en medio de las relaciones y situaciones en las que se cuestiona o se disputa el poder, emerge como la dimensión subjetiva de la construcción colectiva de la vida humana, impensable sin una heterogeneidad de posturas que continuamente entran en tensión o acuerdo; se instaura entonces en el plano del conflicto, el desacuerdo, la lucha por el reconocimiento, pero también de las alianzas y la coordinación conjunta de acciones. ${ }^{9}$

Las tensiones se producen "entre" colectividades con identidades políticas que defienden intereses diferenciados en contextos de circulación del poder ${ }^{10}$. Ahora bien, si las tensiones políticas se ubican en las relaciones humanas, no se puede pensar que de ellas derive solamente una subjetividad instituyente, lo cual significaría reconocer a una de las subjetividades intervinientes de modo unilateral. Precisamente es la idea de relación, como condición de posibilidad de las subjetividades, lo que también lleva a admitir que una subjetividad instituyente no se puede producir sino en relación con otro tipo de subjetividades.

La subjetividad política deviene en medio de las tensiones; no entre los sujetos y una estructura social inmóvil y monolítica, sino propiamente "entre" sujetos -individuales o colectivos-, algunos de los cuales representan, de manera consciente o inconsciente, los intereses de esa estructura y otros que pretenden posicionarse en contra o por fuera de ella. En otras palabras, el orden social hegemónico también tiene una dimensión subjetiva que se expresa en sentidos y prácticas políticas. Aunque los ordenamientos sociales tienden a reificarse no son externos a los sujetos, sino que se reproducen a través sus acciones. Por ello se entiende que aún las resistencias tienen lugar en el seno de los mismos ejercicios de poder frente a los que se oponen (Del Valle, 2012), ya que en los mismos órdenes hegemónicos pueden subsistir los potenciales subjetivos que en algún momento logran generar dialécticamente su transformación. Por el contrario, también es posible que lo que tuvo carácter instituyente en un momento llegue a sedimentarse formando parte de lo instituido, puesto

8 Por eso más que de subjetividad política en general, parece más adecuado hablar de subjetividades políticas en plural.

9 Si bien el poder está en el centro de las relaciones políticas, algunos actores buscan burlarlo, erosionarlo, develarlo, pero no necesariamente detentarlo.

10 Con base en los presupuestos de Arendt (1997), Portela y Portela (2010) afirman: "Allí donde los hombres son iguales no hay espacio público, sólo necesidades comunes propias del hombre en tanto especie animal." (p.137) 
que, como lo ha señalado notablemente la Teoría Crítica, ciertas prácticas que en un momento histórico determinado tienen un carácter progresista, pueden servir más tarde a las condiciones sociales de opresión (Horkheimer, 1937/1974). De la misma manera, las prácticas políticas no convencionales tienden a transformarse en convencionales (Montero, 1995).

Como se ha sostenido hasta ahora, a la subjetividad política le es inherente un potencial de transformación de su propia configuración y de la realidad, pero no se puede asegurar en qué medida se objetivará en un momento dado, desconociendo la movilidad que se acaba de señalar, en la que se involucran las fuerzas materiales, pero también las fuerzas subjetivo-políticas que pugnan por impedirlo. La conciencia de estos bordes del desarrollo subjetivo, resguarda de un nuevo esencialismo que se les ha criticado a las posturas posmodernas, consistente en darle una primacía ontológica a los aspectos simbólicos y lingüísticos de la intersubjetividad humana, demeritando las condiciones culturales-histórico-materiales de su producción, que, si bien tampoco son definitivas, se constituyen en el trasfondo que condiciona la construcción discursiva (Moya \& Ema, 2003). Es por esto que no hay que perder de vista el efecto incierto de las dinámicas y el devenir de las subjetividades políticas, incluyendo las críticas.

La complejidad que caracteriza a las fuentes y los efectos de la subjetividad política, que no están exentos de resultar contradictorios, hacen pensar que no se trata de una configuración homogénea sino heterogénea, que se organiza en pliegues (Foucault, 1991 citado en Cubides, 2007), y se construye en medio de las tensiones y superposiciones entre adscripciones a múltiples comunidades políticas por parte de los sujetos, que incluso se gestan de manera simultánea. ${ }^{11}$ De ahí que en este marco resulta inadecuada una idealización del sujeto político, que reanima subrepticiamente la concepción moderna del sujeto racional, según la cual él encarnaría necesariamente una postura crítica y des-identificatoria frente a la forma de las relaciones sociales dominantes; más bien, se hace imprescindible considerar al sujeto con sus contradicciones e inconsecuencias ${ }^{12}$. La consideración del carácter situado y concreto de los sujetos políticos permite dar cuenta de su multiplicidad y poner entre paréntesis una imagen abstracta e ideal que el sujeto político debería encarnar y que se espera encontrar en las realidades que se investigan. El estudio de la subjetividad política tiene, como toda actividad teórica, una intencionalidad política; en este caso existe un propósito explícito por parte de los autores de visibilizar las posibilidades críticas y emancipadoras del sujeto. Sin embargo, para el necesario rescate de estas líneas de fuga y resistencias, no habría que negar que estas subjetivaciones se generan en medio de un orden social también politizado. Reconocer esto, por supuesto, no implica posponer la tarea urgente de dilucidar qué condiciones o procesos posibilitan la configuración de subjetividades políticas de orientación crítica, pero tampoco desestimar el estudio, desde una perspectiva crítica, de otro tipo de construcciones subjetivas que posibilitan la pervivencia del estado de cosas. ${ }^{13} \mathrm{La}$ necesidad de estudiar los elementos subjetivos y no sólo objetivos -especialmente económicos- que han posibilitado la ilustración, pero también los malestares de la civilización, ha sido esbozada desde hace tiempo con la consigna de investigar "las condiciones subjetivas de la irracionalidad objetiva" (Adorno, 1995/ 2004, p. 39).

\footnotetext{
11 La multiplicidad de los desarrollos subjetivos, estaría vinculada a la densidad de información, diferenciación de las adscripciones asociativas de los individuos y creciente autonomía en la construcción de identidades que caracterizan a los nuevos movimientos sociales en la sociedad contemporánea (Torres, 2009). Otros autores también resaltan el carácter múltiple, dispar y fragmentario de la subjetividad en la actualidad, pero afirman que la subjetividad es al mismo tiempo una: la subjetividad capitalista (Guattari,1992, citado en Aquino, 2013), producida por las políticas de subjetivación del capitalismo (Rolnik, 2003).

12 Es decir, considerar sus ambigüedades, incongruencias y múltiples despliegues, y por lo tanto, distanciarse de una mirada romántica y esencialista como la que critica Gergen (1996).

13 Narváez (2014), por ejemplo, investiga de qué manera los imaginarios sociales en torno a las organizaciones estudiantiles universitario fortalecen conductas instituidas de estigmatización y apatía hacia dichos procesos.
} 
Pág 143

El desencanto, desinterés, escepticismo o pereza hacia lo político, son la expresión de lo que Martínez y Cubides (2012) pretenden problematizar y que describen como una subjetividad funcional al mercado y a la cultura dominante, a la explotación y la subordinación de un sistema que se beneficia de la actitud pasiva, apática y acrítica de los sujetos.
Reconocer, aunque sea implícitamente, los múltiples despliegues de la subjetividad política, es lo que permite a los autores postular, sin caer en aporías, por un lado la existencia de un sujeto político que activamente construye con otros sus realidades en la vida cotidiana, por medio de acuerdos y negociones del poder, y por otro lado, diagnosticar la "desubjetivación de la política" (González, 2012), en relación a un ámbito gubernamental dominado por las castas profesionales de políticos y partidos que ponen a la política por encima de la sociedad y de sus procesos vivos. Efectivamente, los mismos autores que tienden a reivindicar el lugar del sujeto en la constitución de su mundo como productor de sus realidades, incluyendo la política, señalan simultáneamente la situación de sujetación o sometemiento en la que los sujetos se encuentran en razón de su integración al régimen económico y político actual. Por ejemplo, Alvarado et al. (2008) se preguntan: “ipor qué a pesar del potencial para actuar en la historia, en la construcción de país, las personas nos enclaustramos en el ámbito de lo privado y dejamos que nuestros países sean construidos por otros?" (p. 28).

Esta paradoja en el devenir de las subjetividades políticas estriba en que los sujetos, que efectivamente construyen la realidad a través de sus sentidos y prácticas, simultáneamente se pueden sentir inconformes y sometidos frente a una realidad que experimentan como ajena. Esta condición paradojal ha sido señalada por Morin (1995), quien muestra cómo la noción de sujeto es a la misma vez evidente y no evidente. Esta situación contradictoria podría entenderse mejor si se apela una vez más a la multitud de pliegues y despliegues que asume la subjetividad política y que lleva a pensar que existe una dimensión suya aun cuando el sujeto se nombra a sí mismo como apático o desinteresado por lo público. En efecto, el desencanto, desinterés, escepticismo o pereza hacia lo político, son la expresión de lo que Martínez y Cubides (2012) pretenden problematizar y que describen como una subjetividad funcional al mercado y a la cultura dominante, a la explotación y la subordinación de un sistema que se beneficia de la actitud pasiva, apática y acrítica de los sujetos. Podría argumentarse que la conformación de esta clase de subjetividades responde a unos intereses políticos de dominación y por tanto también son un pliegue de la subjetividad política. Por otro lado, también se puede plantear que la "apatía política" no es simplemente un "vacío" de sentido, de afecto y significación, es decir, una ausencia de subjetividad, sino más bien una subjetividad que expresa una antipatía frente a eso que se rechaza en relación a la política, y que además se acompaña de discursos y acciones que privilegian el repliegue en la vida privada. No obstante, los sujetos que se aíslan siguen construyendo el mundo social con sus acciones y omisiones, aunque posiblemente no se trate de la realidad que afirman desear. Se habla aquí de una subjetividad política que reproduce una realidad que a la vez se padece como si le fuera ajena, por lo cual podría hablarse de una subjetividad política enajenada ${ }^{14}$. También cabe decir que muchas de esas subjetividades que se han denominado como 'apáticas', tienen de hecho un contenido crítico que sin embargo no ha trascendido hacia un proyecto emancipatorio.

Estas llamadas subjetividades "apáticas" son ejemplo de una producción subjetiva situada en el entramado social, cuyos orígenes, funcionalidad y efectos pueden no ser claros para los mismos individuos, lo que demuestra una vez más el carácter socialmente construido de la subjetividad política. De la misma manera, las prácticas de liberación y de reflexión también se producen socialmente y no son consecuencia de una mismidad aislada:

14 En este punto se apela al clásico concepto de enajenación, según el cual lo que es producido por el hombre, se enfrenta a él como algo extraño, como un poder independiente del mismo productor (Marx, 1968), por vía de un proceso de cosificación. 
El sujeto se construye activamente a través de prácticas de sí, pero estas prácticas no son sin embargo algo que se invente el individuo mismo, constituyen esquemas que él encuentra en su cultura y que le son propuestos, sugeridos, impuestos por su cultura, su sociedad, su grupo social (Foucault, 1996, citado por Herrera \& Garzón, 2014).

Aunque es posible hablar de configuraciones subjetivas individuales (González. 2002), y afirmar que "el sujeto político es el que aprende a distinguirse, apropiarse y posicionarse como ser único, con pensamiento y acción auténtica" (Alvarado et al., 2012b, p. 859), el individuo no construye sus condiciones de vida desde un lugar de autonomía al margen de toda dependencia (Morin, 1995), sino que necesita de otro y, específicamente en un marco democrático, la base para la negociación de lo público pasa por reconocer a ese otro como un igual en legitimidad y poder para crear.

Ante la diversidad de formas socialmente construidas que puede adquirir la subjetividad política, parece pertinente no sólo considerar las relaciones agonistas entre los defensores declarados del status quo y los sujetos erguidos en resistencias, sino también las relaciones entre estos y aquellos que desconfían de ambas formas de actividad política, pero que no por ello dejan de configurar un pliegue de subjetividad, por más que se rehúsen a ocupar el lugar de sujetos políticos en tanto agentes ${ }^{15}$. Así mismo, resulta necesario reconocer la diversidad de las subjetividades políticas que se disputan el reconocimiento y la legitimidad de sus intenciones y acciones en el ámbito público ${ }^{16}$. De allí que la revitalización de la política, según coinciden en plantear diversos autores (García, 2014; González, 2012; Vargas et al., 2009; Torres, 2009), tendría lugar desde planos como los movimientos sociales y la proliferación de demandas políticas de grupos que no necesariamente tiene un proyecto político con adscripción a una ideología clásica, sino que partiendo de la lecturas sobre sus contextos, buscan que sus acciones tengan un impacto en la forma en que se organiza la vida en común. Aquí se inscriben, por ejemplo, las asociaciones comunitarias que, sin demandar directamente al Estado, se organizan frente a las vulneraciones a las que se ven expuestas desde apuestas por la lúdica, la seguridad alimentaria, la comunicación comunitaria, la protección del territorio, etc., expresando subjetividades políticas paralelas a aquellas que se afilian a movimientos partidistas o contra-hegemónicos.

El carácter procesual, sistémico y recursivo de lo subjetivo conlleva a que la subjetividad política se entienda entonces, no como un segmento de la realidad concreta, cuyos límites puedan ser fijados con precisión, sino como el sistema de sentidos subjetivos que constituyen y son constituidos en el campo de las relaciones políticas, y que por tanto se activan en momentos y espacios de vivencia de dichas relaciones, que se sabe, se experimentan en diferentes espacios sociales en medio de tensiones, conflictos y posiciones contrapuestas. Si se quisiera recurrir a una imagen, el carácter plural de la subjetividad política no podría representarse como un sólo tejido, liso y transparente, sino como el despliegue de múltiples subjetividades políticas que a su vez incluyen pliegues irregulares.

Para finalizar, cabe decir que el considerar la subjetividad política en la pluralidad de sus formas, coincide con el replanteamiento conceptual de la "política" que ha

15 La agencia se puede entender como la emergencia de "un acontecimiento que incorpora novedad ante un trasfondo de sedimentaciones que funcionan como su condición de posibilidad" (Ema, 2004, p.3), y que tradicionalmente ha sido considerada como una producción consciente de los sujetos.

16 Por ejemplo, Samanamud (2006) señala la diversidad en el posicionamiento político de los jóvenes del Alto (Bolivia); caracteriza diferentes grupos de jóvenes, mostrando los elementos comunes de su politización (discriminación, marginación, pobreza vivida), pero también sus diferencias a la hora de posicionarse frente al sistema político vigente, que van desde la identificación con él hasta su deslegitimación radical. 
Pág 145

Si bien se reconoce la posibilidad de transformación de la subjetividad correlativa a cambios del orden social y a procesos de emancipación, estas posibilidades sólo se desarrollan cuando existen las condiciones simbólicas y materiales para ello, en un marco espacio-temporal concreto. tenido lugar en las ciencias sociales y que tiene como pretensión trascender la circunscripción de la política únicamente a su forma institucionalizada Estado-céntrica y permite transitar hacia un horizonte de significación que vislumbra lo político en los ejercicios de poder y resistencia presentes en los ámbitos de la vida cotidiana, que no necesariamente pasan por el Estado sino donde lo vecinal, lo privado, los cuerpos, adquieren sentido político, incluso entre quienes no desean transformar sino sólo conservar valores, roles, símbolos, etc. Esta ampliación del concepto de política no renuncia a su especificidad, que tiene que ver, como se ha dicho, con las relaciones conflictivas que se instauran en el plano público, sino que reconoce que la forma política de tramitar los lazos sociales está presente en los diversos espacios de circulación del poder y asume formas muy variadas. Como consecuencia de ello, las investigaciones sobre subjetividad política han tenido como objetivo común reconocer las alternativas de vinculación política de las personas según sus formas de vida e intereses, en los micro-espacios sociales, conformando alternativas de organización de la existencia colectiva y formas de vivir lo público (Muñoz-López \& Alvarado, 2011; Samanamud, 2006; Vargas et al., 2009). No obstante, se reitera la importancia de que no se desconozca la diversidad de la subjetividad política, que además de ubicarse en diversos escenarios, se sigue desplegando en formas convencionales de vivir la política, pero incluso también desde las construcciones que generalmente se han reconocido como "apáticas".

\section{Conclusiones y sugerencias}

En primer lugar, las tendencias en el tratamiento de la subjetividad política analizadas en la primera parte del texto nos conducen a pensar que, primero, la subjetividad política no puede considerarse aisladamente de la subjetividad social, que integra diversos ámbitos de vivencia de lo político. Segundo, la subjetividad política puede ser entendida en su particularidad como construcción de sentidos subjetivos relativos a lo público, espacio de relaciones políticas orientadas a la disputa y negociación que suscita la vida en común y que envuelve los intentos de tramitación de conflictos surgidos entre posturas, intereses y necesidades diferentes. Tercero, estas relaciones políticas se producen en medio de condiciones socio-históricas, ejercicios de poder y formas instituidas de ordenamiento social que atraviesan a los sujetos. De ahí que la subjetividad política se desarrolle en medio de las tensiones entre las tendencias subjetivas que tienden a la perpetuación de dichas condiciones y aquellas en procura de instituir otras formas de circulación del poder en las relaciones sociales. En cuarto y último lugar, si bien se reconoce la posibilidad de transformación de la subjetividad correlativa a cambios del orden social y a procesos de emancipación, estas posibilidades sólo se desarrollan cuando existen las condiciones simbólicas y materiales para ello, en un marco espacio-temporal concreto.

Por otra parte, en los estudios sobre la subjetividad política se traen a colación una serie de categorías asociadas que permitirían dar cuenta de dimensiones, procesos de constitución y expresiones de ella, que se despliegan de manera recursiva en su producción. Entre ellas se encuentran:

La afectividad: se la considera una dimensión esencial, ya que la vida política de encuentros/desencuentros con los otros siempre está cargada afectivamente. Los afectos, placenteros o displacenteros, se encarnan en las experiencias concretas con las que se forma la subjetividad política y actúan como catalizadores de posicionamientos políticos. 
Cuerpo político: el cuerpo es portador de subjetividad política en tanto aloja prácticas de dominación, pero también de liberación. Además, el cuerpo es intervenido, usado y expuesto continuamente en el proceso de la militancia política. Lleva en sí las marcas de las experiencias políticas y es el lugar de experiencia de los afectos políticos. Encarna lo que no se puede narrar, pero también lo que se simboliza de los discursos políticos.

Reflexividad: como acto que permite volver sobre sí (ampliando el yo, haciendo memoria) para pensarse y reinterpretarse, se instaura como proceso transformador de la subjetividad política.

Procesos agenciantes de la subjetividad política: esta categoría se refiere a experiencias, acontecimientos y condiciones socio-históricas que movilizan la capacidad política del sujeto y por tanto agencian la configuración de subjetividades políticas. Procesos organizativos de acción política y social: se posicionan como escenarios privilegiados para la formación, transformación, afirmación y expresión de subjetividades políticas, al crearse compromisos colectivos en torno a reivindicaciones políticas (por ejemplo, los Movimientos Sociales).

Socialización política: incluye diferentes escenarios y experiencias formadoras de la subjetividad política, en las que circulan sentimientos, valores, creencias, conocimientos y capacidades relativas a la vida política, a través de contenidos políticos explícitos, pero también de la vivencia de prácticas y modos de relación.

Acción política: se entiende simultáneamente como expresión y como proceso productor de subjetividad política. Es la realización viva de la subjetividad política al tratarse de la materialización o concreción de los posicionamientos subjetivos orientados a la transformación de las condiciones de vida.

Por último, el texto presenta la propuesta de que la categoría subjetividad política se pluralice para que se asuma como subjetividades políticas, que sean consideradas en la diversidad de sus despliegues, puesto que ellas emergen en la construcción colectiva de la vida humana, impensable sin una heterogeneidad de posturas que continuamente entran en tensión o acuerdo. Las tensiones que caracterizan al mundo político incluyen a diversos actores y, por lo tanto, parece pertinente no sólo considerar las relaciones agonistas entre los defensores declarados del status quo y los sujetos erguidos en resistencias, sino también las relaciones entre estos y aquellos que desconfían de ambas formas de actividad política, pero que no por ello dejan de configurar un pliegue de subjetividad, por más que se rehúsen a ocupar el lugar de sujetos políticos en tanto agentes.

De lo anterior se deriva la sugerencia de que los estudios sobre subjetividad política no dejen de lado este aspecto tensionante y conflictivo que es propio de la política, de ahí que no sólo se ponga la mirada en las subjetividades críticas o instituyentes, sino que también se estudien, desde una perspectiva crítica, otro tipo de construcciones subjetivas asociadas a los actores que tradicionalmente se han considerado "despolitizados" y a los que se movilizan buscando mantener lo instituido. Por último, resulta pertinente que desde un horizonte epistemológico se profundice en el estudio de las articulaciones, relaciones y diferencias que existen entre las diversas tradiciones teóricas de las que los investigadores sobre subjetividad política se valen para fundamentar sus propuestas. 


\section{Referencias}

Adorno, T. (1955/2004). Sobre la relación entre Psicología y Sociología. En Tiedemann (Ed.), Escritos Sociológicos I: Obra completa, 8. Madrid: Ediciones Akal.

Alvarado, S. V., Ospina H. F., Botero, P., \& Muñoz, H. (2008). Las tramas de la subjetividad política y los desafíos a la formación ciudadana en jóvenes. Revista Argentina de Sociología, (11), 19-43. Recuperado de http://www.scielo.org.ar/pdf/ras/ v6n11/v6n11a03.pdf

Alvarado, S. V., Botero, P., \& Ospina, H, F. (2010). Subjetividades Políticas: sus emergencias, tramas y opacidades en el marco de la acción política. Mapeo de 61 experiencias con vinculación de jóvenes en Colombia. Utopía y Praxis Latinoamericana, 15(50), 39-55. Recuperado de http://www.redalyc.org/articulo. oa?id=27915750004

Alvarado, S. V., Ospina-Alvarado, M. C., \& García, C. M. (2012). La subjetividad política y la socialización política, desde las márgenes de la psicología política. Revista Latinoamericana de Ciencias Sociales, Niñez y Juventud, 10(1), 235-256. Recuperado de http://revistaumanizales.cinde.org.co/index.php/Revista-Latinoamericana/article/view/597/326

Alvarado, S. V., Patiño, J., \& Ospina, M. C. (2012a). Reflexiones sobre la construcción social del sujeto joven vinculado a experiencias de acción política en Colombia: acontecimientos, movilizaciones, poderes. En C. Piedrahíta, A. Díaz, \& P. Vommaro, (Comp.), Subjetividades políticas: desafíos y debates latinoamericanos ( $\mathrm{pp}$. 203-234). Bogotá: Universidad Distrital Francisco José de Caldas. Recuperado de http://biblioteca.clacso.edu.ar/clacso/coediciones/20130218032232/Subjetividadespoliticas.pdf

Alvarado, S. V., Patiño, J. A., \& Loaiza, J. A. (2012b). Sujetos y Subjetividades Políticas: El caso del movimiento juvenil Álvaro Ulcué. Revista Latinoamericana de Ciencias Sociales, Niñez y Juventud, 1(10), 855-869. Recuperado de http://revistaumanizales.cinde.org.co/index.php/Revista-Latinoamericana/article/view/743/387

Alvarado, S.V. (2014). Ampliación de la comprensión de los procesos de configuración de subjetividades políticas de niños, niñas y jóvenes en Colombia desde una perspectiva alternativa de desarrollo humano: tránsitos y aprendizajes. En C. E. Vasco (Dir. Aca.), Socialización política y configuración de subjetividades. Construcción social de niños, niñas y jóvenes como sujetos políticos, (17-53 pp.). Bogotá. D.C.: Siglo del Hombre Editores.

Aquino,A.(2013).Lasubjetividadadebate.Sociológica(80),259-278.Recuperadodehttp:// www.scielo.org.mx/scielo.php?pid=S0187-01732013000300009\&script=sci arttext

Arendt, H. (1997). ¿Qué es la política? Barcelona: Editorial Paidós.

Bonvillani, A. (2006). Autoimagen y Emocionalidad. Reflexiones en torno a la indagación de la subjetividad política de jóvenes a través de la técnica de grupo de discusión. En: Memorias de las XIII Jornadas de Investigación y Segundo Encuentro de Investigadores en Psicología del Mercosur. Facultad de Psicología Universidad de Buenos Aires, Buenos Aires, 422-425. Recuperado de http://www. aacademica.org/000-039/385.pdf

Bonvillani, A. (2012). Hacia la construcción de la categoría Subjetividad Política: una posible caja de herramientas y algunas líneas de significación emergentes. En C. Piedrahíta, A. Díaz, \& P. Vommaro, (Comp.), Subjetividades políticas: desafíos y debates latinoamericanos (pp. 191-202). Bogotá: Universidad Distrital Francisco José de Caldas. Recuperado de http://biblioteca.clacso.edu.ar/clacso/coediciones/20130218032232/Subjetividadespoliticas.pdf 
Bonvillani, A. (2013). Saberes apasionados: horizontes de construcción de conocimiento de las Subjetividade(s) Política(s). En C. Piedrahíta, A. Díaz, \& P. Vommaro. (Comp.), Acercamientos metodológicos a la subjetivación política: debates latinoamericanos, (pp. 83-100). Bogotá: Universidad Distrital Francisco José de Caldas- Clacso. Recuperado de http://biblioteca.clacso.edu.ar/clacso/ gt/20140425024728/AcercamientosMetodologicosALaSubjetividad.pdf

Castoriadis, C. (1997). Ontología de la creación. Bogotá: Ensayo y Error.

Cubides, H. (2007). Política y subjetividad, experiencia o cuidado de sí y la creación de otros mundos. Revista de Ciencias Humanas, (37), 55-67. Recuperado de http:// revistas.utp.edu.co/index.php/chumanas/article/view/1133/619

Del Valle, N. (2012). Entre poder y resistencia. Tras los rastros de la política en Foucault. Revista Enfoques: Ciencia Política y Administración Pública, 10(17), 147-168. Recuperado de http://www.redalyc.org/articulo.oa?id=96024879008

Díaz, A. (2007). Subjetividad e institucionalidad educativa. Revista de Ciencias Humanas UTP, (37), 91-99. Recuperado de http://revistas.utp.edu.co/index.php/chumanas/article/view/1147/633

Díaz, A. (2012a). Devenir Subjetividad Política: Un Punto de Referencia sobre el Sujeto Político. (Tesis presentada como requisito parcial para optar al título de Doctor en Ciencias Sociales, Niñez y Juventud). Centro de Estudios Avanzados en Niñez y Juventud, Universidad de Manizales - CINDE, Manizales. Recuperado de http:// biblioteca.clacso.edu.ar/Colombia/alianza-cinde-umz/20130401053108/TesisAlvaroDG.pdf

Díaz, A. (2012b). Subjetividad política encorpada. Revista Colombiana de Educación, (63), 111-128. Recuperado de http://www.scielo.org.co/pdf/rcde/n63/n63a7

Díaz, A. (2014). Algunos trazos de subjetividad política desde una narrativa autobiográfica. En S.V. Alvarado, \& H. F. Ospina. (Ed), Socialización Política y Configuración de Subjetividades (pp. 139-180). Bogotá: Siglo del hombre Editores.

Díaz, A., \& González, F. (2005). Subjetividad: una perspectiva Histórico Cultural. Conversación con el psicólogo cubano Fernando González Rey. Universitas Psychologica, 4(3), 373-383. Recuperado de http://www.redalyc.org/articulo. oa?id=64740311

Díaz, A., \& González, F. (2012). Subjetividad política y psicologías sociales críticas en Latinoamérica: ideas a dos voces. Univesitas Psychologica, 11(1), 325-338. Recuperado de http://www.redalyc.org/articulo.oa?id=64723234026

Díaz, A., Salamanca, L. A., \& Carmona, O.L. (2012). Biopolítica, Subjetividad Política y "Falsos Positivos". En C. Piedrahíta, A. Díaz \& P. Vommaro, (Comp.), Subjetividades políticas: desafíos y debates latinoamericanos (pp. 47-62). Bogotá: Universidad Distrital Francisco José de Caldas. Recuperado de http://biblioteca.clacso.edu. ar/clacso/coediciones/20130218032232/Subjetividadespoliticas.pdf

Domínguez, M. I., \& Castilla, C. (2011). Prácticas participativas en grupos juveniles de Ciudad de la Habana. Revista Latinoamericana de Ciencias Sociales, Niñez y Juventud, 1(9), 141-160. Recuperado de http://revistaumanizales.cinde.org.co/ index.php/Revista-Latinoamericana/article/view/349/212

Ema, J. (2004). Psicología social: Del sujeto a la agencia (a través de lo político). Athenea Digital, (6), 1-24. Recuperado de http://www.raco.cat/index.php/Athenea/ article/viewFile/34133/33972

Freire, P. (1985). Pedagogía del oprimido. Madrid: Siglo XXI Editores.

García, R. (2013). La carnavalización del mundo como crítica: risa, acción política y subjetividad en la vida social y en el hablar. Athenea Digital, 13(2), 121-130. Recuperado de http://www.psicologiasocial.uab.es/athenea/index.php/atheneaDigital/article/view/GarciaRodriguez 
García, C. (2014). Subjetividad y género: entre los sustancial y lo efímero. En S.V. Alvarado, \& H. F. Ospina. (Ed), Socialización Política y Configuración de Subjetividades (pp. 81-120). Bogotá: Siglo del Hombre Editores.

Garcés, A. (2011). Juventud y comunicación. Reflexiones sobre prácticas comunicativas de resistencia en la cultura hip hop de Medellín. Signo y Pensamiento, 30(58), 108-128. Recuperado de http://www.redalyc.org/pdf/860/86020038008.pdf

Gergen, K. (1996). Realidades y Relaciones: Aproximación a la Construcción Social. Barcelona: Paidós.

Gómez, M. R. (2011). Batuta Caldas-Colombia: un programa de formación musical que deviene en formación ciudadana. Revista Latinoamericana de Ciencias Sociales, Niñez y Juventud, 2(9), 649-668. Recuperado de http://revistaumanizales. cinde.org.co/index.php/Revista-Latinoamericana/article/view/465/257

González, F. (2002). Sujeto y subjetividad: Una aproximación histórico-cultural. México: Thomson.

González, F. (2007). Posmodernidad y subjetividad: distorsiones y mitos. Revista de Ciencias Humanas UTP (37), 7-25. Recuperado de http://revistas.utp.edu.co/index.php/chumanas/article/view/1135/623

González, F. (2008). Subjetividad social, sujeto y representaciones sociales. Revista Diversitas: perspectivas en psicología, 4(2), 225-243. Recuperado de http://www. usta.edu.co/otraspaginas/diversitas/doc pdf/diversitas 8/vol.4no.2/articu$\underline{\text { lo } 1 . p d f}$

González, F. (2012). La subjetividad y su significación para el estudio de los procesos políticos: sujeto, sociedad y política. En C. Piedrahíta, A. Díaz, \& P. Vommaro, (Comp.), Subjetividades políticas: desafíos y debates latinoamericanos (pp. 11-30). Bogotá: Universidad Distrital Francisco José de Caldas. Recuperado de http://biblioteca.clacso.edu.ar/clacso/coediciones/20130218032232/Subjetividadespoliticas.pdf

Herrera, J., \& Garzón J. (2014). Sujeto, subjetividad y ciencias sociales. En. S.V., Alvarado, \& H. F., Ospina. (Ed), Socialización Política y Configuración de Subjetividades (pp. 55-80). Bogotá: Siglo del hombre Editores.

Horkheimer, M. (1937/1974). Teoría Crítica. Buenos Aires-Madrid: Amorrortu editores.

Imhoff, D., Gutierrez, Y., \& Brussino, S. (2011). Jóvenes y ciudadanía: indagación acerca del modo de ejercicio de la ciudadanía de los/as jóvenes a partir de la relación de las orientaciones psicológicas de la politización juvenil con la participación política. Revista Tesis, (1), 1, 21-38.

Lara-Salcedo, L. M. (2010). Potencial de las narrativas en la investigación de subjetividades de las y los jóvenes desvinculados de los grupos alzados en armas, en su proceso de integración a la vida civil. Magis, Revista Internacional de Investigación en Educación, 2 (4), 357-370. Recuperado de http://www.redalyc.org/ pdf/2810/281021692008.pdf

Lozano, M. (2008). Los procesos de subjetividad y participación política de estudiantes de psicología de Bogotá. Revista Diversitas: Perspectivas en Psicología, 4(2), 345-357. Recuperado de http://www.scielo.org.co/scielo.php?pid=S1794$\underline{99982008000200011 \& \text { script }=\text { sci arttext }}$

Martínez, M., \& Cubides, J. (2012). Acercamientos al uso de la categoría de 'subjetividad política' en procesos investigativos. En C. Piedrahíta, A. Díaz, \& P. Vommaro, (Comp.), Subjetividades políticas: desafíos y debates latinoamericanos (pp. 169-190). Bogotá: Universidad Distrital Francisco José de Caldas. Recuperado de http://biblioteca.clacso.edu.ar/clacso/coediciones/20130218032232/Subjetividadespoliticas.pdf 
Marx, K. (1968). Manuscritos de economía y filosofía. Madrid: Alianza Editorial.

Marx, K. (2009). La cuestión judía. Barcelona: Anthropos.

Montero, M. (1995). Modos alternativos de acción política. En M. Montero, \& V. García, Psicología de la acción política, (pp. 90-109). Buenos Aires: Paidós.

Morin, E. (1995). La noción de sujeto. En Fried Schnitman, D. (Comp.), Nuevos paradigmas, cultura y subjetividad. Buenos Aires: Paidós.

Mouffe, CH. (2007). En torno a lo político. Buenos Aires: Fondo de cultura económica.

Moya, J., \& Ema, J. (2003). Mirada caleidoscópica al construccionismo social. Política y Sociedad, 40(1), 5-14. Recuperado de http://revistas.ucm.es/index.php/POSO/ article/view/POSO0303130005A/23754

Muñoz-López, S. M., \& Alvarado, S. V. (2011). Autonomía en movimiento: reflexión desde las prácticas políticas alternativas de jóvenes en Colombia. Revista Latinoamericana de Ciencias Sociales, Niñez y Juventud, 1(9), 115-128. Recuperado de http://revistaumanizales.cinde.org.co/index.php/Revista-Latinoamericana/ article/view/347/210

Narváez, J. (2014). Imaginario social, organización estudiantil y subjetividades políticas universitarias. Tesis psicológica, 9(1), 114-129. Recuperado de http://www. redalyc.org/pdf/1390/139031679010.pdf

Ocampo, A. M., Méndez, S., \& Pavajeau, C. (2008). Las subjetividades como centro de la formación ciudadana. Universitas Psychologica, 7(3), 837-851. Recuperado de http://www.scielo.org.co/pdf/rups/v7n3/v7n3a17.pdf

Palacios-Mena, N., \& Herrera-González, J. D. (2013). Subjetividad, socialización política y derechos en la escuela. Magis Revista Internacional de Investigación en Educación, 5 (11), 413-437. Recuperado de http://www.redalyc.org/articulo. oa? id $=281028437008$

Pedroza, B., Mesa, J., \& Bustos, V. (2013). Las subjetividades políticas que circulan en los espacios virtuales de socialización, el caso de la página de Facebook Universitarios con Petro. Prospectiva, (18), 319-346. Recuperado de http://revistaprospectiva.univalle.edu.co/index.php/prospectiva/article/view/2495

Piedrahíta, C. (2012). Una perspectiva en investigación social: el pensar crítico, el acontecimiento y las emergencias subjetivas. En C. Piedrahíta, A. Díaz, \& P. Vommaro, (Comp.), Subjetividades políticas: desafíos y debates latinoamericanos (pp. 31-46). Bogotá: Universidad Distrital Francisco José de Caldas. Recuperado de http://biblioteca.clacso.edu.ar/clacso/coediciones/20130218032232/Subjetividadespoliticas.pdf

Piedrahíta, C. (2013). Apuntes metodológicos para una perspectiva investigativa del feminismo de la diferencia sexual. Esfera, 2(2), 29-44. Recuperado de http:// revistas.udistrital.edu.co/ojs/index.php/esfera/article/view/5791/7259

Portela, J., \& Portela, H. (2010). Subjetividad política en la Formación de Formadores. Estudio sobre la Licenciatura de Ciencias Sociales de la Universidad de Caldas. Revista Latinoamericana de Estudios Educativos, 6(2), 129-154. Recuperado de http://www.redalyc.org/pdf/1341/134126048007.pdf

Quintana, L. (2012) Singularización política (Arendt) o subjetivación ética (Foucault): dos formas de interrupción frente a la administración de la vida. Revista de Estudios Sociales, (43), 50-62. Recuperado de http://www.redalyc.org/articulo. oa?id=81523250005

Rancière, J. (2006). Política, policía, democracia. Santiago de Chile: LOM Ediciones.

Retamozo, M. (2009). Orden social, subjetividad y acción colectiva: Notas para el estudio de los Movimientos sociales. Athenea Digital, (16), 95-123. Recuperado de http://www.psicologiasocial.uab.es/athenea/index.php/atheneaDigital/article/ view/560 
Retamozo, M. (2011) Sujetos políticos: decisión y subjetividad en perspectiva posfundacional. Ideas y valores, IX (147), 51-64. Recuperado de http://www.revistas. unal.edu.co/index.php/idval/article/view/36772/38744

Samanamud, J. (2006). La subjetividad política de los jóvenes en la ciudad de El Alto. Tinkazos, 9(21). Recuperado de http://www.scielo.org.bo/scielo.php?pid=S1990$\underline{74512006000100007 \& \text { script }=\text { sci arttext }}$

Soto, J. (2001). Psicología Social: Una borrosidad de disciplina. Psicología social: Cinta Moebio, (10), 34-46. Recuperado de http://www.revistas.uchile.cl/index.php/ CDM/article/viewFile/26312/27612

Tassin, E. (2012) De la subjetivación política. Althusser/Rancière/ Foucault/Arendt/ Deleuze. Revista de Estudios Sociales, (43), 36-49. Recuperado de http://res.uniandes.edu.co/view.php/780/index.php?id=780

Torres, A. (2009). Acción colectiva y subjetividad. Un balance desde los estudios sociales. Folios. Segunda época, (30), 51-74. Recuperado de http://www.scielo.org.co/ scielo.php?script=sci arttext\&pid=S0123-48702009000200004\&lng=es\&nrm $=$. pf\&tlng=es

Vommaro, P. (2012). Los procesos de subjetivación y la construcción territorial: un acercamiento desde experiencias de organizaciones sociales en Buenos Aires. En C. Piedrahíta, A. Díaz, \& P. Vommaro (comp.), Subjetividades políticas: desafíos y debates latinoamericanos (pp. 63-76). Bogotá: Universidad Distrital Francisco José de Caldas. Recuperado de http://biblioteca.clacso.edu.ar/clacso/coediciones/20130218032232/Subjetividadespoliticas.pdf

Vargas, V., López, L., \& Guevara, N. (2009). Constitución de sujeto político: historias de vida política de mujeres líderes afrocolombianas. Universitas Psychologica, 8(3), 639-652.

Zemelman, H. (2012). Subjetividad y realidad social. En C. Piedrahíta, A. Díaz, \& P. Vommaro, (comp.), Subjetividades políticas: desafíos y debates latinoamericanos (pp. 235-246). Bogotá: Universidad Distrital Francisco José de Caldas. Recuperado de http://biblioteca.clacso.edu.ar/clacso/coediciones/20130218032232/ Subjetividadespoliticas.pdf

Zibechi, R. (2007). Autonomías y emancipaciones: América Latina en movimiento. Lima: Fondo Editorial de la Facultad de Ciencias Sociales. 